IZA DP No. 9473

A Theory of Intra-Firm Group Design

Semih Tumen

November 2015 


\title{
A Theory of Intra-Firm Group Design
}

\author{
Semih Tumen \\ Central Bank of the Republic of Turkey \\ and IZA
}

Discussion Paper No. 9473

November 2015

\author{
IZA \\ P.O. Box 7240 \\ 53072 Bonn \\ Germany \\ Phone: +49-228-3894-0 \\ Fax: +49-228-3894-180 \\ E-mail: iza@iza.org
}

\begin{abstract}
Any opinions expressed here are those of the author(s) and not those of IZA. Research published in this series may include views on policy, but the institute itself takes no institutional policy positions. The IZA research network is committed to the IZA Guiding Principles of Research Integrity.

The Institute for the Study of Labor (IZA) in Bonn is a local and virtual international research center and a place of communication between science, politics and business. IZA is an independent nonprofit organization supported by Deutsche Post Foundation. The center is associated with the University of Bonn and offers a stimulating research environment through its international network, workshops and conferences, data service, project support, research visits and doctoral program. IZA engages in (i) original and internationally competitive research in all fields of labor economics, (ii) development of policy concepts, and (iii) dissemination of research results and concepts to the interested public.
\end{abstract}

IZA Discussion Papers often represent preliminary work and are circulated to encourage discussion. Citation of such a paper should account for its provisional character. A revised version may be available directly from the author. 
IZA Discussion Paper No. 9473

November 2015

\section{ABSTRACT}

\section{A Theory of Intra-Firm Group Design*}

I develop an intra-firm theory of group design and teamwork in the presence of peer effects. The purpose is to understand the interlinkages between intra-firm group formation and the extent of wage dispersion within the firm. Given a set of heterogeneous workers, the manager faces the challenge of allocating workers into endogenous groups (or teams) to maximize total profits. The optimal allocation features locational proximity between workers with similar productivity levels. I discuss the implications of this allocation on intra-firm wage outcomes. The main idea is that the wage paid to a single worker is determined by the productivity levels of the teammates as well as the worker's own productivity. This means that team composition is critical to understanding the within-firm productivity and wage differentials. I show that intra-firm wage dispersion is more pronounced when workers are more alike within each team and more different across the teams. I provide numerical exercises designed to illustrate how the model's predictions change as the key parameters are varied. One striking result is that a rise in the correlation between education and productivity (this can be interpreted as hiring workers with vocational education) leads to a decline in wage inequality within the firm. I also show that changes in the dispersion of worker efficiency lead to non-monotonic effects on within-firm wage inequality.

JEL Classification: J31, L22, L23, M51, M52

Keywords: group design, peer effects in the workplace, within-firm pay differences, sorting, selectivity

Corresponding author:

Semih Tumen

Research and Monetary Policy Department

Central Bank of the Republic of Turkey

Istiklal Cad. No:10

06100 Ulus, Ankara

Turkey

E-mail: semih.tumen@tcmb.gov.tr

\footnotetext{
* I thank Iwan Barankay, Jesper Sorensen, Yossi Spiegel, Peter Thompson, seminar participants at the Central Bank of the Republic of Turkey, and the participants of the 2013 Turkish Economic Association conference in Izmir for useful comments. I am particularly grateful to William Greene (the editor), an Associate Editor, and an anonymous referee for extremely helpful suggestions. The views expressed here are of my own and do not necessarily reflect those of the Central Bank of the Republic of Turkey. All errors are mine.
} 


\section{Introduction}

For many production processes, especially in large firms, output per worker is not only a function of the characteristics of a single worker, but also of the characteristics of the peers working close to her. ${ }^{1}$ The "peer effects" viewpoint in production is of particular importance for jobs requiring teamwork and communication. ${ }^{2}$ It imposes a major organizational challenge on firms in terms of the optimal assignment of workers to peers (or teams), as a misallocation may result in inefficiencies and severe output loss. For example, Lazear (1998) argues that complementarities in production among co-workers make it economically desirable for a firm to form groups or teams. This viewpoint is also important to understand the role of peer effects on the properties of within-firm wage structure, as the wage payments to a single worker is affected by the productivity levels of her co-workers as well as her own [Ledford, Lawler, and Mohrman (1995)].

The theoretical framework I develop in this paper addresses three related, but distinct, questions. First, how to consider the optimal assignment of heterogeneous workers to endogenously defined peer groups or teams in the workplace? Second, how to assess the role of endogenously formed peer groups on wage differences within the firm? Third, how to uncover the connections between team composition (i.e., the intra-team mix of worker characteristics) and wage outcomes? Existence of strong empirical evidence highlighting the importance of peer effects in the workplace [see, for example, Ichino and Maggi (2000), Hamilton, Nickerson, and Owan (2003), Mas and Moretti (2009), and Bandiera, Barankay, and Rasul (2010)] necessitates the development of a coherent theoretical framework to enhance our understanding of how peer effects shape within-firm resource allocation and the resulting wage outcomes. The fact that peer groups are endogenously formed within the firm makes the problem more interesting. This paper embeds the idea of endogenous teams into a hedonic pricing model, which makes it possible to study group design in the presence of worker heterogeneity in multiple dimensions.

\footnotetext{
${ }^{1}$ For expositional purposes, the worker is a "she" and the manager is a "he" throughout the paper.

${ }^{2}$ The concept of positive spillover externalities in the workplace is not new and goes back to Marshall (1890). Lazear and Shaw (2007) provide evidence that the incidence of teamwork has been steadily increasing over time.
} 
The first question is related to within-firm organizational practices. Given a set of heterogeneous workers, the manager faces the challenge of allocating workers into groups to maximize total profits. Empirical evidence suggests strong complementarities between individual- and group-level productivities. In other words, the marginal product of a worker increases with the productivity levels of the peers she works with. The production externalities reflect the benefits to any worker from the existence of other workers nearby. In an optimal allocation, employees with similar productivities should work close to each other. Due to complementarities, locational proximity of highly productive workers leads to greater profits.

Interestingly, this doesn't imply a perfect segregation story in the sense that workers with superior efficiency levels should work close to each other in isolation and the less efficient ones should not interact with them. The intuition is as follows. Teams are composed of heterogeneous workers. I define productivity as a three-dimensional object: efficiency, education, and luck. ${ }^{3}$ There is a positive correlation between efficiency of a worker and her education. The manager observes and acts on only efficiency and education, forming expectations on the luck component. He forms groups or teams in production to maximize total profits. In each group, there is a balance of highly efficient but less educated and less educated but more efficient workers. The groups are ranked by the quality of this mix. Accordingly, worker productivity is defined as a combination of efficiency and education. As a result, team composition, which is endogenously determined, is an important element of the analysis.

The second question, which is closely linked to the first one, investigates the impact of group design on the within-firm wage structure in the equilibrium. In particular, I analyze the relationship between the manager's decisions on group formation and wage inequality within the firm. The key assumption is that the members of a team are paid similarly, but wages differ across teams. I show that team composition is a critical element in explaining withinfirm wage differentials. When selectivity is stronger (i.e., when workers within a team are more alike), the degree of sorting goes up and teams become more different from each other. In such a case, being a part of a better group will contribute more, on average, to an individual

\footnotetext{
${ }^{3}$ The luck component can be interpreted as an independent idiosyncratic shock that affects the worker's output.
} 
worker's output. As a result, the wage equation will tend to be a convex function of team quality and the degree of within-firm wage inequality will go up.

The answer to the third question is immediate. Stronger sorting and selectivity leads to greater pay differentials within a firm. Specifically, stronger selectivity is implied by smaller withinthe-team productivity differentials, whereas stronger sorting is implied by larger productivity differentials across teams. ${ }^{4}$ I conclude that managers will be more willing to pay for teamwork when team membership complements the individual worker's effort significantly. In other words, stronger peer effects raise the manager's valuation of teamwork.

In a nutshell, the main contribution of the paper can be summarized as follows. I consider each worker's output in the production process as a combination of her own characteristics and the characteristics of her co-workers. Worker characteristics are heterogeneous and the heterogeneity is multi-dimensional. The manager optimally allocates workers into (endogenous) teams based on these characteristics. Wages are determined based on each group's productivity, which is a combination of the characteristics of the workers selected in the group. In other words, wages are determined consistent with the hedonic pricing logic. So, the paper contributes to the literature by providing a hedonic pricing interpretation to intra-firm group design. Another contribution is that the paper shows that team composition is an important determinant of wage dispersion within the firm. In particular, I show that intra-firm wage dispersion is more pronounced when workers are more alike within each team and more different across the teams.

That worker heterogeneity is multi-dimensional provides a rich basis for comparative statics exercises and, therefore, for policy. Everything else constant, increased dispersion of the years of school education within the firm leads to increased wage inequality. If the manager wants to reduce wage differentials across teams, he has to hire workers with similar education levels. A larger correlation between education and productive efficiency of workers (i.e., if the worker's

\footnotetext{
${ }^{4}$ Formally speaking, the terms "sorting" and "selectivity" can be best understood by comparing the population and withinteam distributions of productivity. Specifically, if the gap between within-team versus population-level average productivities describe the degree of sorting. Similarly, the gap between within-team versus population level variance of productivity describes the degree of selectivity. These two terms jointly define the structure of teamwork within the firm. See page 13 for a much more detailed description of these two terms.
} 
are hired on the basis of their vocational education) within the firm leads to decreased wage inequality, since selectivity and sorting will be weaker. When this is the case, efficiency and education become more substitutable, which reduces the incentives for bunching workers with respect to their efficiency levels. ${ }^{5}$

The analysis builds on the framework developed by Nesheim (2001), and extended by Ioannides (2008, 2011) and Tumen (2011, 2012). The starting point is a simple social interactions story, which falls into the category of endogenous contextual effects. ${ }^{6}$ The key element is the demand for an intra-firm amenity variable: group-level productivity. The manager's willingness to pay for each worker is a function of the group that the worker is assigned. Notice that a selection process operates in the background: more efficient workers are assigned to better groups and are paid higher wages. I provide exact selection formulations that resemble the Heckman's selfselection equations. These selection equations rationalize the sorting of workers into teams. I show how one can go from the demand equation for the amenity variable to the associated selection and sorting equations.

The plan of the paper is as follows. The next section provides explicit links between the model and the relevant literatures. Section 3 presents the model and outlines a solution strategy that results in analytical solutions for the equilibrium objects featured by the model. Section 4 discusses the implications of this equilibrium for intra-firm wage outcomes. Section 5 concludes.

\section{Related Literature}

The backbone of the model is the classical hedonic pricing idea: worker heterogeneity is multi-dimensional and these multiple characteristics are priced jointly in determining wage outcomes. Because of this joint pricing idea, the model can be classified within a particular class of hedonic models, called the Tinbergen-Rosen framework. ${ }^{7}$ The manager places a worker

\footnotetext{
${ }^{5}$ Section 4 presents the details of this result as well as further results from additional comparative statics exercises.

${ }^{6} \mathrm{~A}$ contextual effect means that the social influence comes from the group-level characteristics. It is endogenous because the group formation is determined within the model. See Manski $(1993,2000)$ for a more precise definition of the related concepts.

${ }^{7}$ See Tinbergen (1956), Rosen (1974), and Ekeland, Heckman, and Nesheim (2002, 2004).
} 
into a group based on a certain decision-making rationale, which rests on the characteristics of the workers in the group. More specifically, the manager brings together workers with similar characteristics in each group, but the groups are different from each other. There is a natural hierarchy between the groups in the sense that more productive workers are sorted into better groups. Such an allocation maximizes the firm's profits. The main idea is the existence of production externalities. This force increases worker productivity if similar workers are close by. $^{8}$

The key result in the paper is that workers with similar productivities are brought together in teams by the manager in the optimal allocation. The whole idea behind the sorting and selectivity results in the model is based on this positive correlation between worker-level and group-level characteristics. There is new and compelling empirical evidence supporting the validity of this result. Bandiera, Barankay, and Rasul (2010) find that a worker's productivity is considerably higher when she works close to peers who are more productive than her, and considerably lower when she works with less productive peers. This suggests that within group heterogeneity may be beneficial in increasing the output that low-productivity workers produce, but it is detrimental to highly productive ones. As a result, the existence of large within-group heterogeneity (in productivity) contradicts the whole idea behind production externalities. They present suggestive evidence that group formation within the firm follows the principle of positively assortative matching in the sense that workers with similar abilities tend to be selected into similar groups in the optimal allocation. ${ }^{9}$ I embed an analytically tractable Heckman selection argument into the model, which governs sorting and determines the pricing of teamwork. ${ }^{10}$

This idea is also closely related to the literature on the effect of team composition on produc-

\footnotetext{
${ }^{8}$ Similar ideas can be found in the urban economics literature under the topic of "agglomeration economies". See, for example, Fujita (1989). This idea is also prevalent in residential sorting models [see Ioannides (2011) for a review].

${ }^{9}$ This is tangentially related to the "homophily principle." In other words, the similarities between individuals make them more likely to form social groups within each other. See McPherson, Smith-Lovin, and Cook (2001), Marmaros and Sacerdote (2006), and Currarini et al. (2009) for further reading.

${ }^{10}$ Heckman selection-correction procedure develops a framework to deal with non-randomly selected samples from the population and removes the associated biases [see Heckman (1979)]. The theoretical model developed in this paper embeds a Heckman selection argument, because the problem of non-random sorting of more productive workers into more productive teams is a clear case of self-selection. Thus, the tools developed by Heckman can be used to analyze the patterns of sorting and selectivity within the firm.
} 
tivity. The main focus in this literature is to investigate whether a team is more productive when it consists of more heterogeneous workers or more homogeneous ones. The results are rather mixed in this literature. For example, Hamilton, Nickerson, and Owan (2003) find that more heterogeneous teams are more productive and the members of those teams receive higher wages. The main idea in their paper is that exchange of information is more effective in heterogeneous teams and, therefore, productivity is higher. Bandiera, Barankay, and Rasul (2005), however, argue that there may be negative externalities to the more productive members of the group under the heterogeneity scenario. They argue that, in the presence of these negative externalities, piece rates rather than pay-for-relative-performance schemes will sustain team productivity. Similarly, Prat (2002) shows that, with positive complementarities, the team should be composed of more homogeneous workers, while, with negative complementarities, heterogeneity is optimal. In my model, there are positive complementarities between individual effort and team effort. Like Prat (2002), I show that such a setup produces the result that productivity is higher when teams are composed of more homogeneous workers. Unlike other papers, I argue that within-group similarities induce heterogeneity across groups, which is a reflection of sorting and selectivity.

I argue that as teams become more different from each other, wage dispersion within the firm goes up. This finding is also consistent with the empirical literature. Bandiera, Barankay, and Rasul (2011) show that as the within-team productivity differentials increase, so does the inequality in pay across teams. ${ }^{11}$ The novelty that this paper introduces is that it connects the team incentives literature to the hedonic pricing literature. Worker characteristics exhibit multi-dimensional heterogeneity, which allows me to perform a rich set of comparative statics exercises - a task that I carry out in Section 4. These exercises shed light on the structure of within-firm wage dispersion in the presence of teamwork and peer effects.

A critical assumption in the model is that wages are paid based on team-level productivity rather than individual productivity. In other words, wages are similar within each group and

\footnotetext{
${ }^{11}$ Lazear (1989), Drago and Garvey (1998), and Carpenter, Matthews, and Schrim (2010) argue that increased team-level pay differences might reduce cooperation within teams. But I abstract from such strategic complexities.
} 
there are significant wage differentials across groups. There is a large literature supporting the validity of this assumption. Theoretically, papers including Akerlof and Yellen (1990), Levine (1991), and Hibbs and Locking (2000) argue that wage compression within a team of workers performing similar task ensures cohesiveness and improves productivity. ${ }^{12}$ This is consistent with the "within-team" pay equality assumption that I adopt in this paper. Papers in the rank-order tournaments literature [see, for example, Lazear and Rosen (1981) and McLaughlin (1988)] establish that existence of pay dispersion across teams may be beneficial for productivity. This is also captured by the model. In a nutshell, this assumption corresponds to the conjecture that there should be a correct balance of incentive schemes and monitoring practices within the firm [see also Belfield and Marsden (2003)]. ${ }^{13}$ The assumption is also valid empirically. There is ample evidence that social comparison and fairness promotes payment of similar wages within a team. For example, recent work by Cohn, Fehr, Herrmann, and Schneider (2011) document that, in a team of two equally-paid workers, performance decrease after an equal wage cut for both workers is much less than the performance decrease after cutting only one of the worker's wage. In other words, social comparisons affect productivity. In a related work, Card, Mas, Moretti, and Saez (2012) document that job satisfaction and productivity depend on relative pay comparisons. Given these findings, introducing withinteam pay differences (or pay-for-performance) is subject to the free-rider problem [Kandel and Lazear (1992)].

There are also some concrete examples of equal pay within the team. This assumption is particularly valid in environments, where the team members are averse to inequitable outcomes. ${ }^{14}$ Papers including Farrell and Scotchmer (1988) and Encinosa, Gaynor, and Rebitzer (2007) document that in several industries, including fishing, law partnerships, and medicine, equal pay within the team is a common practice. Some large companies also explicitly adopt equal-pay policy across team members in their human resource management practices - see, e.g., Toyota. Although the equal-pay assumption has empirical validity, there are also many

\footnotetext{
${ }^{12}$ See also Milgrom (1988) and Milgrom and Roberts (1990).

${ }^{13}$ Lallemand, Plasman, and Rycx (2009) provide an excellent review of the related literature. See also Gibbons and Waldman (1999).

${ }^{14}$ See, e.g., Camerer (2003), Fehr and Schmidt (2006), Bartling and von Siemens (2010), and Bose, Pal, and Sappington (2010).
} 
examples of unequal pay. I prefer to maintain the equal-pay assumption for two main reasons. First, it considerably simplifies the algebra. Dividing a large number of workers into an indeterminate number of groups within an equilibrium framework is not an easy task. The assumption of equal pay across team members based on group-level productivity reduces the level of mathematical complexity. Second, introducing unequal pay across team members requires a more careful modeling of performance monitoring. To abstract from incentive problems and associated modeling complexities, I choose a theoretical framework in which all team members are paid equally, but the pay differs across teams. This is equivalent to assuming that there is perfect peer monitoring.

Although I conjecture that relaxing the equal-pay assumption can potentially alter some of the results, the qualitative predictions of the model will likely remain unaltered. One viable channel through which the equal-pay assumption could be relaxed is to introduce wage determination based on observed individual-level characteristics, such as education and experience. In such a case, the main prediction of the model - that is, better workers will be more likely to work together - will not change, since individual- and group-level productivities are complementary in the model. So, the returns to relaxing the equal-pay assumption will most likely be less than the cost of additional complexity it will bring. Moreover, pricing workers based on observable characteristics is also an equally controversial topic in the labor economics literature. It is very well-known that pay gaps persist among observationally equivalent workers - i.e., even after controlling for all observable characteristics that can potentially affect labor market earnings. To avoid these additional issues, the equal-pay assumption will be the maintained assumption throughout the paper.

There is a recently emerging literature attempting to relate the recent increase in the overall wage inequality to the increased degree of within-firm sorting of more productive workers to more productive teams/tasks. The econometric framework to identify the degree of sorting is developed by Abowd, Kramarz, and Margolis (1999). For example, Card, Heining, and Kline (2013) use workplace-level labor market data to show that part of the increase in wage inequality in Germany can be attributed to increased inequality within the workplace. Other 
recent papers exploring the workplace component of wage inequality include Goux and Maurin (1999), Gruetter and Lalive (2009), and Eeckhout and Kircher (2011). The common finding in

all these papers is that increased assortativeness of workers across teams/tasks/firms explain a considerable share of the increase in wage inequality in major industrialized economies. The current paper attempts to provide a theoretical background through which within-firm sorting and selectivity patterns can govern the patterns of wage inequality within the firm.

\section{The Model}

\subsection{Theoretical Basis}

There is a large firm, which is endowed with a continuum of workers. Workers are heterogeneous in their characteristics, which are described by a three-dimensional vector $\boldsymbol{\alpha}=$ $\left(\alpha_{e}, \alpha_{s}, \alpha_{\ell}\right) \in \mathbb{R}^{3}$, where $\alpha_{e}$ is the worker's efficiency in production, $\alpha_{s}$ is the years of schooling, and $\alpha_{\ell}$ is an independent luck component. The population distribution of worker characteristics is a trivariate normal distribution such that $\boldsymbol{\alpha} \sim \mathcal{N}(\boldsymbol{\mu}, \boldsymbol{\Sigma})$, where

$$
\boldsymbol{\mu}=\left[\begin{array}{c}
\mu_{e} \\
\mu_{s} \\
0
\end{array}\right] \text { and } \boldsymbol{\Sigma}=\left[\begin{array}{ccc}
\sigma_{e e} & \sigma_{e s} & 0 \\
\sigma_{e s} & \sigma_{s s} & 0 \\
0 & 0 & \sigma_{\ell \ell}
\end{array}\right]
$$

Notice that $\alpha_{\ell} \Perp\left(\alpha_{e}, \alpha_{s}\right)$, where $\Perp$ denotes statistical independence. For practical purposes (i.e., to be able to go back and forth between normals and log-normals), I exponentiate the vector of worker characteristics and denote heterogeneity with $e^{\boldsymbol{\alpha}}$, which is $\log$-normally distributed. This transformation will be maintained for the rest of the paper.

Intra-firm groups are indexed by $x \in \mathbb{R}$, where $x$ is defined as

$$
x=\mathbb{E}\left[e^{\alpha_{e}} \mid \mathcal{D}_{\boldsymbol{\alpha}}(x)\right]
$$

In words, each group (or team) is described by the average efficiency of those workers $\boldsymbol{\alpha} \mid \mathcal{D}_{\boldsymbol{\alpha}}(x)$, who are brought together in group $x$ by the manager through the decision rule $\mathcal{D}_{\boldsymbol{\alpha}}(x)$. This 
formulation implies that the manager targets the mean efficiency within the group. The description of efficiency within the context of this model is standard: given $x, e^{\alpha_{s}}$, and $e^{\alpha_{\ell}}$, the individual-level efficiency $e^{\alpha_{e}}$ stands for the worker's output per unit of effort or time. Keeping the other variables constant, workers with a higher $\alpha_{e}$ are capable of producing more output. Similarly, teams with more efficient workers are capable of producing more output. Notice that Equation (3.2) is a truncated mean of the log-normal random variable $e^{\alpha_{e}}$, where the truncation is performed based on the manager's choices. Below I show that $x$ is an equilibrium object and I provide the details of the manager's decision rule, which is based on a profit maximization problem.

The objective of the manager is to maximize the total profits of the firm. To achieve this goal, he considers each worker's output separately and places workers to endogenously-formed groups in the best way possible. There are two fundamental ideas. First, there are complementarities between worker-level efficiency in production and the group-level productivity. Second, the manager acts on these complementarities and brings together workers to maximize the total output. The nature of the equilibrium outcome - that I describe below in great detail - communicates the key properties of the rules of group design and the associated wage outcomes.

Each worker's production is determined by four factors. The first factor is a Cobb-Douglas combination of the worker's own characteristics, $\left(e^{\eta \alpha_{e}} e^{\alpha_{s}}\right)$, where $\eta>0$ is the relative importance of the worker's efficiency versus her education. The second factor is a function, $x^{\beta}$, of the mean efficiency of her co-workers, where $\beta>0$ describes the strength of peer effects in production. If $\beta$ is high, then the average efficiency of the team members affects the individual worker's productivity substantially. The third factor is managerial ability, $A$. And the final factor is a luck component, which is independent from all the other factors and is unknown to the manager at the time the allocation decision is made. To be concrete, the manager expects the contribution of the luck component to be $\mathbb{E}\left[e^{\alpha_{\ell}}\right]$, which (by log-normality) is equal to $e^{\frac{1}{2} \sigma_{\ell \ell}}$. For notational simplicity, I denote this positive constant number with $L>0$. 
Formally, the manager solves the following problem for each worker:

$$
\max _{x}\left\{A L x^{\beta}\left(e^{\eta \alpha_{e}} e^{\alpha_{s}}\right)-w(x)\right\}
$$

where $w(x)$ is the wage payment to workers in group $x .{ }^{15}$ Wages are paid based on grouplevel productivity rather than individual-level productivity. But this does not mean that the implications for wage dispersion is limited. Section 4 discusses in depth the implications of this setup for within-firm wage dispersion and inequality. In the rest of this section, I describe a solution strategy for the manager's problem.

The first-order condition is

$$
A L \beta x^{\beta-1}\left(e^{\eta \alpha_{e}} e^{\alpha_{s}}\right)=w^{\prime}(x)
$$

and the second-order condition is

$$
A L \beta(\beta-1) x^{\beta-2}\left(e^{\eta \alpha_{e}} e^{\alpha_{s}}\right)-w^{\prime \prime}(x)<0 .
$$

The first-order condition says that the manager should equate the marginal return from moving the worker to a better group to the marginal cost of it. To provide a sharper definition of Equation (3.2), I take the natural logarithms of both sides in the first-order condition and rearrange the terms, which yields

$$
\ln \left[w^{\prime}(x)\right]-\ln [A L \beta]-(\beta-1) \ln [x]=\eta \alpha_{e}+\alpha_{s}
$$

This expression is the equivalent of the well-known bid-rent equation in the urban economics literature. ${ }^{16}$ The left-hand side is a function of $x$ and the right-hand side is simply a combination of the observable worker characteristics. This equation motivates how the workers are grouped. Consider a given group $x$. Given the parameters, the manager chooses to bring together those workers whose marginal productivities equal $\eta \alpha_{e}+\alpha_{s}$. As a consequence, the

\footnotetext{
${ }^{15}$ The manager plays the role of a social planner aiming to optimally allocate workers across teams within the firm. Other than this role, there is not a formal managerial body or a CEO in the model that decides on operational issues within the firm.

${ }^{16}$ See Ross and Yinger (1999) for an extensive review of the related literature.
} 
group $x$ consists of low-efficiency and high-education workers as well as high-efficiency and low-education ones. The only requirement is that $\eta \alpha_{e}+\alpha_{s}$ has to be equal to the constant index in the left-hand side of Equation (3.6). Although the workers differ in their individual efficiencies and education, their productivities are similar and the manager brings similar workers together to maximize profits. It seems optimal to put low-efficiency workers next to the high-efficiency ones to improve their productivities. But, such an action will be detrimental to the high-efficiency workers, since they work nearby the low-efficiency ones. Therefore, the optimal allocation is to for form intra-firm endogenous teams by bringing together similar workers. The properties of these endogenous teams are discussed below.

The shorthand of Equation (3.6) is simply

$$
\mathcal{D}_{\alpha}(x)=\eta \alpha_{e}+\alpha_{s}
$$

This is the decision rule to rationalize the logic behind the truncated mean [see Equation (3.2)] explained above. Plugging this decision rule into Equation (3.2), the groups are endogenously defined as follows:

$$
x=\mathbb{E}\left[e^{\alpha_{e}} \mid \mathcal{D}_{\alpha}(x)=\eta \alpha_{e}+\alpha_{s}\right] .
$$

There exists an analytical solution for equilibrium $x$ as a function of the model elements and, in what follows, I outline a solution strategy to derive this closed-form solution. This decision rule truncates the population distribution of worker efficiency, $\alpha_{e}$, for the purpose of generating group-level distributions which are conditional on managerial decision rules. In other words,

$$
\alpha_{e} \mid\left(\mathcal{D}_{\alpha}(x)=\eta \alpha_{e}+\alpha_{s}\right) \sim \mathcal{N}\left(\hat{\mu}_{e}(x), \hat{\sigma}_{e e}(x)\right)
$$

where $\hat{\mu}_{e}(x)$ and $\hat{\sigma}_{e e}(x)$ are the mean and the variance of the worker efficiency distribution in group $x$. The intuition is simple. The manager forms groups, indexed by $x$, by bringing together workers with similar characteristics. In each group $x$, there is a conditional distribution of $\alpha_{e}$. In other words, each group is a mix of workers whose individual-level characteristics 
are defined by the managerial decision rule $\eta \alpha_{e}+\alpha_{s}$. Using the well-known properties of the truncated normal distribution, it is easy to see that

$$
\hat{\mu}_{e}(x)=\mu_{e}+\left[\mathcal{D}(x)-\left(\eta \mu_{e}+\mu_{s}\right)\right] \frac{\eta \sigma_{e e}+\sigma_{s s}}{\eta^{2} \sigma_{e e}+2 \eta \sigma_{e s}+\sigma_{s s}}
$$

and

$$
\hat{\sigma}_{e e}(x)=\hat{\sigma}_{e e}=\sigma_{e e}-\sigma_{e} \frac{\left(\eta \sigma_{e e}+\sigma_{s s}\right)^{2}}{\eta^{2} \sigma_{e e}+2 \eta \sigma_{e s}+\sigma_{s s}} .
$$

It is clear from the above formulas that the managerial decision rule (3.7) transforms the population distribution of $\alpha_{e}$ into a continuum of conditional normal distributions indexed by $x$. The conditional mean and the conditional variance govern the patterns of sorting and selectivity, respectively. Think of the conditional mean, $\hat{\mu}_{e}(x)$, first. The term $\frac{\eta \sigma_{e e}+\sigma_{s s}}{\eta^{2} \sigma_{e e}+2 \eta \sigma_{e s}+\sigma_{s s}}$ is a positive constant (which has a special meaning, which I describe later). For a highly productive group (i.e., a high $x$ ), the term $\left[\mathcal{D}(x)-\left(\eta \mu_{e}+\mu_{s}\right)\right]$ is positive. As a result, the mean efficiency in group $x$ is greater than the mean efficiency in the population. Similarly, the mean efficiency in a low- $x$ group will be lower than the population mean. This implies that there is positively assortative matching between individual workers and intra-firm groups. Now think of the conditional variance, $\hat{\sigma}_{e e}$. Since $\frac{\eta \sigma_{e e}+\sigma_{s s}}{\eta^{2} \sigma_{e e}+2 \eta \sigma_{e s}+\sigma_{s s}}$ is positive, the variance of worker efficiency in group $x$ is smaller than the population variance. This means that there is selectivity in that the variance in a selected group is smaller than the population variance. ${ }^{17}$ The patterns of $\hat{\mu}_{e}(x)$ and $\hat{\sigma}_{e e}$, i.e., whether they are high or low, are important and have implications for intra-firm equilibrium outcomes.

The key object is $\frac{\eta \sigma_{e e}+\sigma_{s s}}{\eta^{2} \sigma_{e e}+2 \eta \sigma_{e s}+\sigma_{s s}}$, which has a nice interpretation. Think of the regression of a worker's efficiency $\alpha_{e}$ on her marginal productivity $\eta \alpha_{e}+\alpha_{s}$. Formally, the regression model would write

$$
\alpha_{e}=\delta\left(\eta \alpha_{e}+\alpha_{s}\right)+\epsilon
$$

\footnotetext{
${ }^{17}$ This resembles the selectivity (or the control functions) idea due to Heckman (1979).
} 
where $\epsilon$ is an independent error term. The coefficient $\delta$ is simply $\frac{\operatorname{Cov}\left(\eta \alpha_{e}+\alpha_{s}, \alpha_{e}\right)}{\operatorname{Var}\left(\eta \alpha_{e}+\alpha_{s}\right)}$, which can be shown, after simple algebra, to be equal to $\frac{\eta \sigma_{e e}+\sigma_{s s}}{\eta^{2} \sigma_{e e}+2 \eta \sigma_{e s}+\sigma_{s s}}$. The interpretation is the following. If $\delta>0$, then workers with greater efficiency are placed into the groups with greater marginal productivity on average. ${ }^{18}$ This, in turn, implies positive sorting and selectivity.

The effect of an increase in $\delta$ can be interpreted in two related ways. First, it leads to a stronger sorting of workers into groups. This can be seen from the formula for $\hat{\mu}_{e}(x)$. With a higher $\delta$, the difference between the mean efficiency of a group $x$ and that of a group $x+\varepsilon$ is larger for all $x$, for arbitrarily small $\varepsilon>0$. In other words, groups are more different from each other. This is due to the second interpretation: with a higher $\delta$, the variance $\left(\hat{\sigma}_{e e}\right)$ of the group-level distribution of worker efficiency is smaller for all groups. In other words, higher $\delta$ means increased selectivity in the group level. That intra-group variance is smaller means that groups are composed of workers, who are more similar to each other. The main result is that, when $\delta$ goes up, groups are composed of more similar workers and, as a consequence, groups are more different from each other. ${ }^{19}$ This means that sorting is stronger and selectivity is increased, which has implications for intra-firm wage differentials. To derive these implications, some additional algebraic steps are required.

From Equation (3.8) and from the properties of the conditional log-normal distribution,

$$
x=e^{\hat{\mu}_{e}(x)+\frac{1}{2} \hat{\sigma}_{e e}},
$$

which can be rewritten, after substituting in the formulas for $\hat{\mu}_{e}(x)$ and $\hat{\sigma}_{e e}$, as

$$
x=\kappa x^{\delta(1-\beta)} w^{\prime}(x)^{\delta},
$$

where $\kappa=e^{\mu_{e}-\delta\left\{\ln [A L \beta]+\left(\eta \mu_{e}+\mu_{s}\right)\right\}+\frac{1}{2} \hat{\sigma}_{e e}}$ is a positive constant. ${ }^{20}$ Rearranging the terms yields

\footnotetext{
${ }^{18}$ This will be linked to higher and more unequally distributed wages in Section 3.

${ }^{19}$ Notice that the group-level variances are compressed when $\delta$ goes up. But this compression does not produce a meanpreserving spread. The fact that it raises the differences in means across groups is due to the correlation imposed by the decision rule.

${ }^{20}$ The log-normality assumption is not critical for the qualitative nature of the results presented in this paper. However, the log-normality assumption is required to obtain analytically tractable formulas for equilibrium objects such as wages and grouplevel productivity levels. In particular, this assumption is extremely helpful to derive the formulas for sorting and selectivity, since the regression interpretation given in Equation (3.12) critically relies on the normality assumption. The log-normal distribution is also used very often in economics, since various critical variables - such as income, earnings, firm size, firm productivity, human
} 
the differential rents equation

$$
w^{\prime}(x)=\left(\frac{1}{\kappa}\right)^{\frac{1}{\delta}} x^{\frac{1}{\delta}-(1-\beta)} .
$$

Clearly, $w^{\prime}(x)>0$, which means that wages are increasing in the group-level productivity, $x$. If $\frac{1}{\delta}-(1-\beta)$ is greater than zero, then the wage function is convex in group level quality. This means that the pay differentials between the teams are going up in an increasing fashion as $x$ goes up. If $\frac{1}{\delta}-(1-\beta)$ is smaller than zero, then the wage equation is a concave function of $x$. In this case, wage inequality between groups is lower. Integrating out this formula and normalizing $w(0)=0$ yield the wage equation

$$
w(x)=\left(\frac{1}{\kappa}\right)^{\frac{1}{\delta}}\left(\frac{1}{\delta}+\beta\right)^{-1} x^{\frac{1}{\delta}+\beta} .
$$

Since this wage equation normalizes the outside option, $w(0)$, to be equal to zero, I focus on the differential rents equation (i.e., the equation for $\left.w^{\prime}(x)\right)$ to analyze the implications for intra-firm wage dispersion. Section 4 presents a detailed discussion of the wage outcomes within the firm.

Before discussing wages, I present a visual description of the equilibrium allocation of workers across groups. Figure (3.1) summarizes the main results. The red line plots the group-level mean efficiency against the index $x$. For low-efficiency groups, $\hat{\mu}_{e}(x)$ is negative (it is lower than the population mean) and it is positive for groups with high efficiency. At each point along the $x$-axis, there exists a normal distribution $\mathcal{N}\left(\hat{\mu}_{e}(x), \hat{\sigma}_{e}\right)$ characterizing the nature of the sorting and selectivity within the firm. These distributions are plotted in blue. The variance is constant across groups, but the mean is decreasing by definition. Any upward shift in the red curve is necessarily accompanied by a compression in the group-level variance and any downward shift should be accompanied by an increase in the group-level variance. The

capital, and consumption - are empirically shown to be log-normally distributed. Log-normality fits to reality well in general, because it reflects the fact that "high-quality is rare." This is also relevant within the context of the current paper. I conjecture that relaxing the log-normality assumption should not change any of the results as long as the alternative distribution comes from the exponential family - such as exponential, gamma, Pareto, Dirichlet, etc. The only requirement is that there should be a clearly right-skewed distribution with a long right-tail for the results to hold. Without log-normality, however, analytical tractability will be much harder to obtain. 


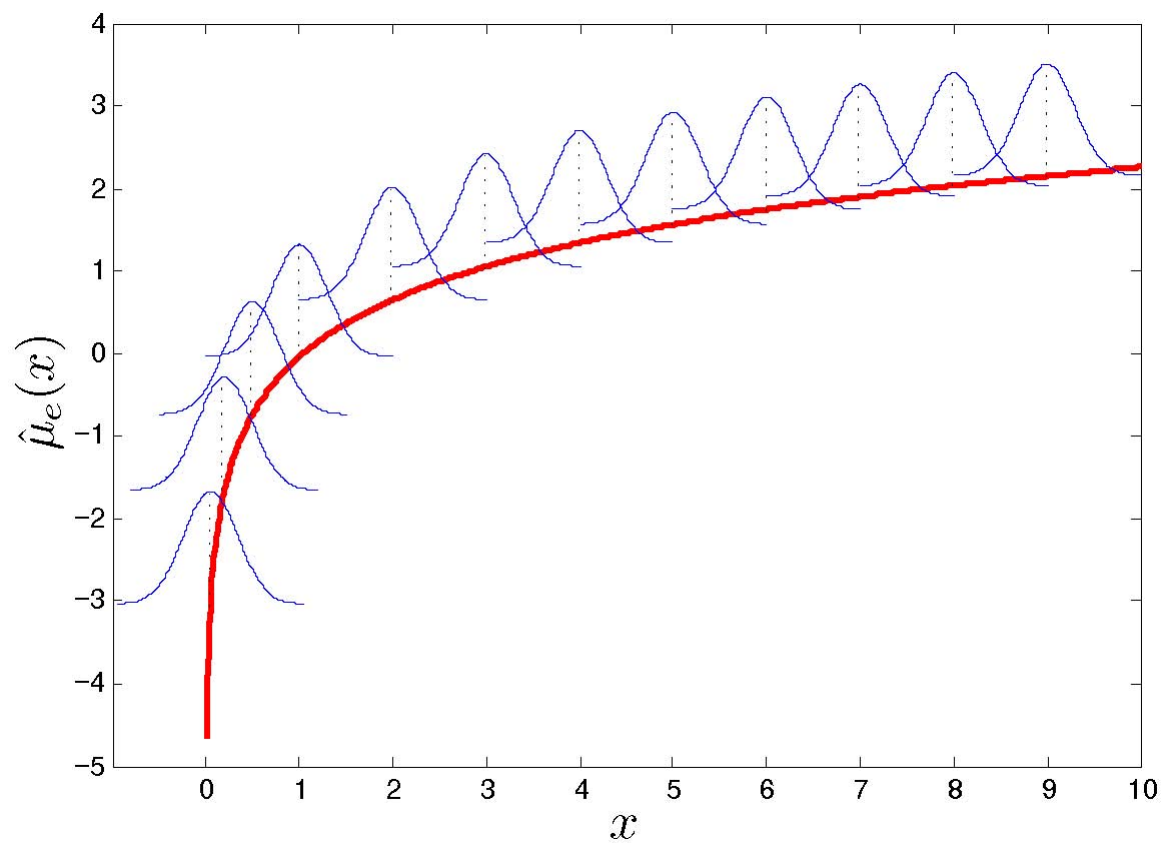

Figure 3.1: A visual RePREsentation of the optimal allocation.

group-level mean efficiency increases quickly at low $x$ levels and then the speed of increase slows down. The concave nature of the red curve is due to the assumption of normal distribution. ${ }^{21}$ The main ideas behind this figure are closely linked to the micro-foundations of the within-firm wage differentials that this model implies. The next section deals with these implications.

The main lessons from the model should perhaps be reemphasized. The manager forms teams within the firm to produce output. Workers with similar productivities are brought together in each team. But this doesn't mean that teams consist of homogeneous workers. In fact, just the opposite is true. The intuition is the following. By definition, the hedonic formulation of the output produced per worker allows me to describe the production process as a function of multiple worker characteristics. Workers are different from each other in terms of these characteristics. $^{22}$ Workers in each group is selected based on the principle given in Equation (3.8). In other words, workers in group $x$ have the same $\eta \alpha_{e}+\alpha_{s}$, which implies that they can differ in their efficiency and schooling levels. Although this decision rule imposes certain

\footnotetext{
${ }^{21}$ The idea is simple. As one moves away from the left tail, incremental improvements in $x$ comes with increased densities of better quality worker groups. Once the mean point is past behind, the incremental improvements in $x$ bring decreasingly smaller contributions to the group quality.

${ }^{22}$ For the sake of analytical tractability, I limit the dimension of the characteristics vector to be two (efficiency and education). In a more elaborate version (or in a version designed for the purpose of empirical applicability), the characteristics vector may be allowed to consist of three or more worker traits.
} 
similarities within the group, it does not rule out intra-group heterogeneity. A natural consequence of the group level sorting is that groups are different from each other, which is the basis for the hedonic pricing function given in Equation (3.16). In the next section, I perform several comparative statics exercises to clarify what this hedonic wage equation can explain.

\subsection{Conceptualization}

In this subsection, I attempt to clarify and interpret some of the concepts introduced in the theoretical model developed in Section 3.1. To start with, the production technology described in Equation (3.3) is a labor-only technology. There is no capital in the model. Following the neoclassical tradition, it is possible to interpret the labor input as "equipped labor" rented to the firm at rate $w$. In this sense, labor productivity can be classified as multi-factor productivity.

Labor productivity is categorized in the paper as two related, but distinct, objects: $(i)$ individual-level labor productivity and (ii) group-level labor productivity. The individuallevel productivity is described by the three-dimensional vector $\boldsymbol{\alpha}$ of worker characteristics. These three dimensions are efficiency, education, and luck. The three-dimensional characteristics vector differs across workers; in other words, workers are different from each other in terms of the efficiency $\left(\alpha_{e}\right)$, education $\left(\alpha_{s}\right)$, and luck $\left(\alpha_{\ell}\right)$ components. Workers with higher individual level productivity are capable of producing more output per unit of input. It is also necessary to emphasize that the individual-level productivity is an exogenous object in the model.

Group-level productivity, however, is defined as the average individual-level productivities of the workers employed in each group. Since the manager matches workers with groups based on an optimization rule, the group-level productivity is an endogenous object-unlike the individual-level productivity - which is determined at the equilibrium. The managerial decision rules yield an explicit mathematical relationship between individual- and group-level productivities. In particular, Equation (3.13) fully characterizes the group-level productivity as an analytically-tractable function of individual-level productivities. The group-level pro- 


\begin{tabular}{cl}
\hline \hline Parameter & Definition \\
\hline$\eta$ & Relative importance of efficiency versus schooling in production \\
$\beta$ & Strength of peer effects (or the effect of teamwork) in production \\
$A$ & Managerial ability \\
$L$ & Mean of the log-normal idiosyncratic uncertainty component \\
$\mu_{e}$ & Mean of worker efficiency in the firm \\
$\mu_{s}$ & Mean of worker education in the firm \\
$\sigma_{e e}$ & Variance of worker efficiency in the firm \\
$\sigma_{s s}$ & Variance of worker education in the firm \\
$\sigma_{e s}$ & Covariance between efficiency and education of workers in the firm \\
\hline \hline
\end{tabular}

Table 1: EXogenous PARAMETERS AND THEIR DEFInitions.

ductivity is a truncated mean of individual-level productivities of the workers employed in each group, where the truncation is performed based on managerial decision rules.

\section{Implications for Intra-Firm Wage Dispersion}

In this section, I perform comparative statics exercises to shed light on the implications of internal group design for wage inequality within the firm. There are nine parameters in the model and what they stand for is summarized in Table (1). These parameters describe the endogenous parameters derived within the model such as $\delta, \kappa$, and so on. Varying these nine exogenous parameters independently has interesting implications for the structure of sorting and wage inequality within the firm.

Figure (4.1) provides a general picture that will be helpful in evaluating the comparative statics exercises. In a nutshell, this figure says that any factor that leads to an increase in the strength of sorting also leads to a compression in within-team variances (i.e., an increase in the degree of selectivity). In such a case, teams are composed of more alike workers, but differences across teams become more pronounced. This can be seen from the left panel in Figure (4.1). Increased sorting and selectivity (defined with red color in the figure), in turn, raises pay inequality within the firm, which is evident from the right panel. The right panel says that the sign of the first derivative of the wage function is now more positive, which implies that the degree of convexity goes up and therefore the difference between the lower and the higher ends of the pay spectrum gets larger. Next I discuss the comparative statics 
results that lead to this conclusion.

\subsection{Comparative Statics}

Higher $\sigma_{e s}$. A rise in $\sigma_{e s}$ means that the correlation between worker efficiency and education is stronger. When this is the case, efficiency and education become more substitutable, which reduces the incentives for bunching workers with respect to their efficiency levels. As a consequence, with higher $\sigma_{e s}$ sorting is weaker and within-group selectivity is less. Note that, in Figure (4.1), the case with higher $\sigma_{e s}$ is denoted in blue in both panels. The reflection in wages is striking: a rise in $\sigma_{e s}$ reduces wage inequality within the firm.

Higher correlation between efficiency and education can be interpreted in two ways: indirect and direct correlations. First, it may suggest that there exists an unobserved ability component, which is positively correlated with both worker efficiency and education. Under this interpretation, workers are more efficient in production when the level of unobserved ability is high. At the same time, the ones with higher unobserved ability are also the ones who are more successful at school. As a result, efficiency and education are indirectly related-i.e., through a third unobserved component. Although, in theory, this is a relevant argument, the empirical research suggests that wage gaps still persist even after accounting for various measures of unobserved ability — such as test scores measuring cognitive and non-cognitive capacities of workers. Second, there is also a more direct interpretation for this positive correlation: vocational training. High positive correlation between efficiency and education can be related to vocational education, because vocational training directly aims at providing skills that can directly influence productivity on the job. There are several papers in the literature reporting evidence in favor of this interpretation. Sala and Silva (2012) find using cross-country data from Europe that vocational education has significantly contributed to labor productivity growth in Europe. A similar finding is also reported by Dearden, Reed, and Van Reenen (2006) using British micro-level data. Based on this second interpretation, the model I develop suggests that hiring workers with vocational training reduces wage inequality within the firm. The reason is that vocational training implies that efficiency and education 

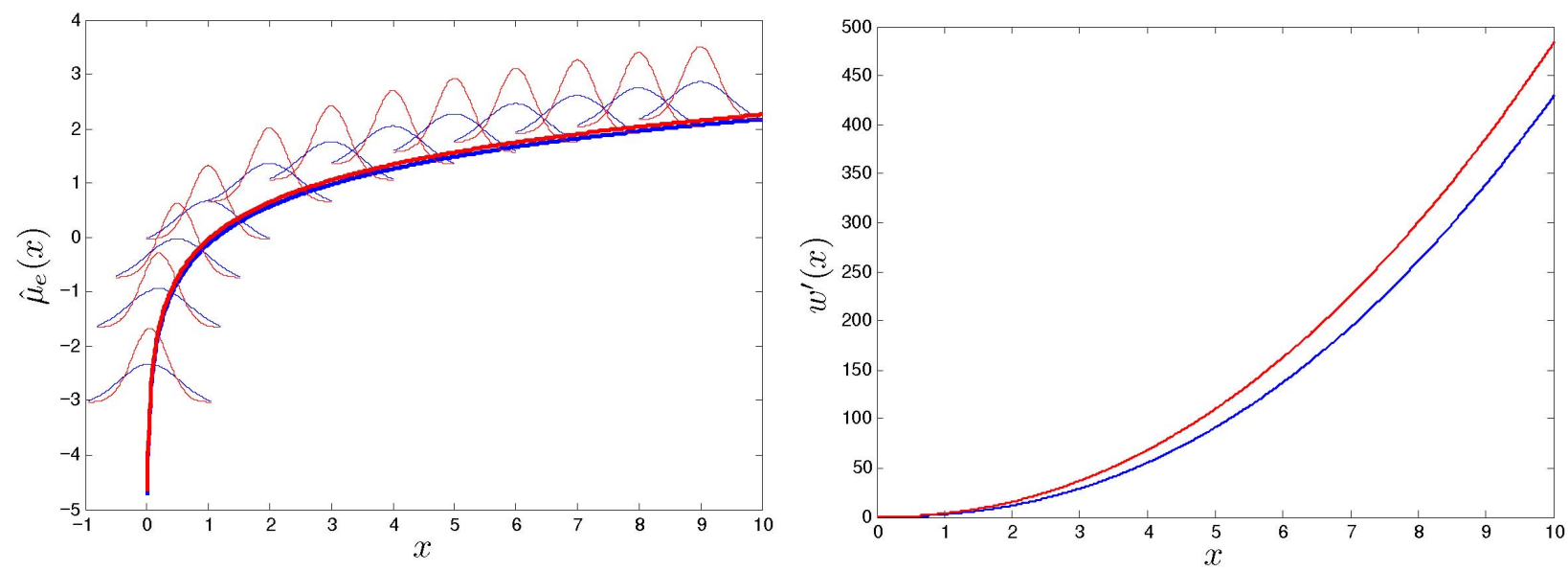

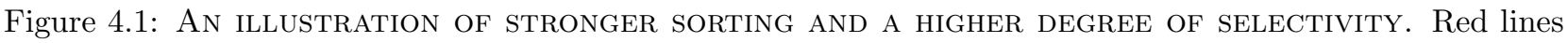
describe the case with increased sorting and selectivity; that is, the group-level means are higher and variances are lower at all $x$ levels.

are more closely related and are better substitutes. This implies that sorting and selectivity are weaker when workers have higher vocational training.

Higher $\sigma_{s s}$. An increase in $\sigma_{s s}$ stands for a more dispersed school education of the workers within the firm. For example, there are more high school dropouts, but there are also more PhDs. Under such a scenario, the dispersion of schooling in each team will also go up. As a response to such a change, the manager will bring together more alike workers in terms of efficiency levels. This is a natural result to expect, since the manager cares about worker efficiency in production rather than education directly. To prevent output loss associated with ending up with more mixed groups, he increases the degree of sorting and selectivity with respect to worker efficiency. As a result, wage inequality goes up.

Higher $\eta$. When $\eta$ goes up, worker efficiency becomes relatively more important versus education and teamwork in the production function. Since the endogenous group formation logic is based on bringing together workers with similar efficiency levels, a rise in $\eta$ provides even more incentives for bunching. The main reason is that increased $\eta$ can be translated into decreased substitutability of efficiency level with other factors of production. As a result, the manager forms groups of more similar workers since the returns to doing so are larger. This, in turn, leads to a reduction in wages for low-productivity groups, while increasing wages in 
high-productivity groups. The impact of $\eta$ on average wages and within-firm wage inequality is ambiguous. Wage inequality within the firm starts rising if the wage increases in the righttail of the productivity distribution dominates the wage decreases on the left. Section 4.2 clearly demonstrates this point.

Higher $\sigma_{e e}$. Increasing $\sigma_{e e}$ has more complex implications for wage inequality. To understand what is going on, think of $\sigma_{e e}$ as taking values in a certain interval $[b, d]$, where $d>b>0$. There exists an intermediate level $\bar{\sigma}_{e e}, d>\bar{\sigma}_{e e}>b$, such that moving from $b$ toward $\bar{\sigma}_{e e}$ decreases the degree of sorting and selectivity, while moving from $\bar{\sigma}_{e e}$ toward $d$ increases it again. In other words, $\bar{\sigma}_{e e}$ is the point, where the degree of sorting and selectivity is minimum, taking other parameters fixed. As a result, I conclude that changes in $\sigma_{e e}$ affects wage inequality in a non-monotonic way; that is, wage inequality is lower at $\bar{\sigma}_{e e}$ and it is higher elsewhere in the interval $[b, d]$. This result suggest that the distribution of efficiency offers the manager another margin of choice. If he targets a low wage inequality within the firm, he can achieve this goal by choosing a worker composition such that $\sigma_{e e}$ is close to $\bar{\sigma}_{e e}{ }^{23}$

Playing with the remaining parameters, i.e., the parameters $\beta, A, L, \mu_{e}$, and $\mu_{s}$, does not alter the structure of sorting and inequality. Varying them affects only the degree of wage inequality within the firm. As expected, increasing $\beta$ (i.e., increasing the returns to teamwork) raises wage inequality, although it does not affect the within-team worker composition. The reason is that changing $\beta$ affects the manager's valuation of teams with respect to each other (rather than team composition). As a result, increasing $\beta$ raises manager's valuation of better groups. Increasing managerial ability, $A$, also extends the degree of within-firm wage inequality, without affecting team composition. An increase in managerial ability raises output for all workers and teams, but this increase is larger in better teams due to complementarities. As a consequence, raising $A$ widens wage dispersion. An increase in $L$ (i.e., reducing the uncertainty imposed by idiosyncratic shocks) also raises wage inequality, since it leads to an improvement in the manager's valuation of the output produced in better groups. Raising the

\footnotetext{
${ }^{23}$ It is also noteworthy that the effect of increasing $\sigma_{e e}$ on wage inequality over the $x$ horizon is irregular, i.e., a higher $\sigma_{e e}$ raises inequality in the lower tail while it increases inequality in the upper tail in a certain interval, whereas in another interval this effect may be reversed.
} 
mean level of schooling, $\mu_{s}$, within the firm also leads to an increase in wage inequality. Again the reason is the existence of complementarities. Finally, a rise in the mean efficiency level, $\mu_{e}$, in the worker population leads to a decline in wage inequality, as expected.

\subsection{A Simulation Exercise}

It will perhaps be useful to perform a simulation exercise for the purpose of providing a more concrete understanding of the theoretical predictions of the model. This will also support the validity of the comparative statics discussion presented above. Remember that each worker is characterized by a three-dimensional vector $\boldsymbol{\alpha}=\left(\alpha_{e}, \alpha_{s}, \alpha_{\ell}\right)$, where $\alpha_{e}, \alpha_{s}$, and $\alpha_{\ell}$ are efficiency, education, and luck, respectively. To simplify the exercise, I shut down the luck component and, instead, define each worker with a two-dimensional vector. I generate 10,000 joint draws for the random variables $\alpha_{e}$ and $\alpha_{s}$, which are potentially positively correlated. The distributions of these two random variables are both standard normal. I analyze the impact of the key parameters - including $\beta$ (strength of peer effects in production), $\eta$ (relative importance of efficiency versus education in production), and $\sigma_{e s}$ (the covariance between efficiency and education) - on the main outcomes of interest. Other parameters, including $A$, $L, \sigma_{e e}, \sigma_{s s}, \mu_{e}, \mu_{s}$, are held fixed. ${ }^{24}$ The outcomes of interest are basically wage [Equation (3.16)], profit per job [Equation (3.3)], and group-level productivity index [Equation (3.13)].

Table (2) summarizes the results. The upper panel fixes $\beta=0.5$ and $\sigma_{e s}=0.5$, and varies $\eta$ in the range of $[0.3,0.7]$. The parameter $\eta$ is a technology parameter and it describes the relative importance of worker efficiency versus worker education in the production. As I mention above, an increase in $\eta$ means that the degree of substitutability between worker efficiency and other factors of production goes down. In such a case, returns to bunching (i.e., forming teams consisting of workers with similar efficiency levels) goes up. As a consequence, wages decline in low-productivity groups, while, in high-productivity groups, wages increase. The overall impact on within-firm average and standard deviation of wages is ambiguous. This ambiguity is confirmed by the simulation results. As $\eta$ goes up, the manager forms more similar groups.

\footnotetext{
${ }^{24}$ See Table (2) for the values of these fixed parameters.
} 
The average wage first goes down, but then picks up. A similar observation is also made for the standard deviation of wages. The balance between the left and right tails of the wage distribution determines the direction of the change in average and the standard deviation of wages. Once the wage increases in the right-tail dominates the decreases in the left tail, both the average and standard deviation of wages start going up. I conclude that the impact of $\eta$ on within-firm wage inequality is non-monotonic and depends on the balance between the movements on the left versus right tail of the wage distribution. This is consistent with the comparative statics exercise performed in Section 4.1. A similar pattern is also observed for profit that the firm receives per-job, although the direction is reversed. As the wage increases on the right tail dominate wage decreases in the left-tail, the per-job average profit of the firm starts going down.

The middle panel of Table (2) fixes $\eta=0.5$ and $\sigma_{e s}=0.5$, and varies $\beta$ in the range of $[0.3,0.7]$. The parameter $\beta$ describes the strength of peer effects in production. In other words, it measures the degree of returns to teamwork. As I explain in Section 4.2, $\beta$ does not affect the magnitude of sorting and selectivity, i.e., it does not alter $x$. However, it changes the wages and profits per job. An increase in $\beta$ leads to a monotonic increase in average and standard deviation of wages, and a monotonic decline in the average and standard deviation of profits per job. This is intuitive. As the importance of teamwork goes up, teams with higher average productivity are paid higher wages relative to the ones with lower average productivity, which leads to an increase in within-firm wage inequality.

Finally, the lower panel of Table (2) fixes $\eta=0.5$ and $\beta=0.5$, and varies $\sigma_{e s}$ in the range of $[0.3,0.7]$. The parameter $\sigma_{e s}$ measures the degree of correlation between efficiency and education levels of the workers. For example, if $\sigma_{e s}$ is high, then a high-efficiency worker is more likely to be high-educated than a low-efficiency worker. The simulation results suggest that the incentives for bunching goes down as $\sigma_{e s}$ increases, in line with the comparative statics exercise. The reason is that efficiency and education become more substitutable as $\sigma_{e s}$ goes up. The degree of sorting declines at the equilibrium, which leads to a decline in average wages. As the groups become similar and the returns to bunching goes down, the within-firm 
wage inequality also declines. On the other hand, the manager makes higher profits per job and the profits are higher in groups with high average productivity levels. At the end, I verify that the insights provided by the comparative statics exercises are supplemented by the simulation exercise.

\section{Concluding Remarks}

In this paper, I analyze the intra-firm organizational practices regarding group design and incentives for teamwork. I argue that, in the presence of complementarities, bringing together workers with similar characteristics is part of an optimal group design strategy. I provide a clear link between such a strategy and within-firm wage outcomes. More specifically, I show that wage inequality within the firm is related to the problem of allocating heterogeneous workers into groups. I provide various comparative statics exercises to clarify the effect of the key parameters on the results. The results of the comparative statics exercises are supplemented by a simulation exercise.

The model features many insights about the sources of within-firm wage inequality. I assess the interplay between team composition - which is endogenous - and wage differentials between teams. One of the main results is that the wage dispersion within the firm is more pronounced when workers are more alike within each team and more different across the teams. This suggests that team composition (i.e., whether teams are more homogeneous or more heterogeneous) is an important determinant of intra-firm wage inequality. An important novelty that this paper introduces is that team effort is priced in a hedonic setting. In other words, the model recognizes that workers are heterogeneous in multiple dimensions, teams are composed of these heterogeneous workers, and, as a consequence, teamwork is priced based on the composition of these multiple characteristics within each team. This rich setting allows me to perform various comparative statics exercises that yield interesting outcomes. One particular result that deserves more theoretical and empirical attention is that employing more workers with vocational education is associated with decreased wage differentials within the firm. I leave exploring the underlying micro-foundations of this result for future research. 
The current setup is limited with the internal labor market within a firm. An important extension would be to incorporate an external labor market into this setup. Such an extension would incorporate hiring from outside the firm and workers' decision to quit. Allowing worker's entry and exit opens the door for the managerial group design decisions to be affected by developments outside of the firm. Studying this extension requires a substantial reworking of the current model setup, which I also leave for future research. 


\section{References}

Abowd, J. M., F. Kramarz, and D. Margolis (1999): "High Wage Workers and High Wage Firms," Econometrica, 67, 251-333.

Akerlof, G. A. And J. L. Yellen (1990): "The Fair Wage-Effort Hypothesis and Unemployment," Quarterly Journal of Economics, 105, 255-283.

Bandiera, O., I. Barankay, And I. Rasul (2005): "Social Preferences and the Response to Incentives: Evidence from Personnel Data," Quarterly Journal of Economics, 120, 917962.

(2010): "Social Incentives in the Workplace," Review of Economic Studies, 77, 417458.

(2011): "Team Incentives: Evidence from a Team-level Experiment," Unpublished manuscript, London School of Economics.

Bartling, B. And F. A. von Siemens (2010): "Equal Sharing Rules in Partnerships," Journal of Institutional and Theoretical Economics, 166, 299-320.

Belfield, R. And D. Marsden (2003): "Performance Pay, Monitoring Environments, and Establishment Performance," International Journal of Manpower, 24, 452-471.

Bose, A., D. Pal, And D. E. M. Sappington (2010): "Equal Pay for Unequal Work: Limiting Sabotage in Teams," Journal of Economics 83 Management Strategy, 19, 25-53.

Camerer, C. (2003): Behavioral Game Theory, Princeton, NJ: Princeton University Press.

Card, D., J. Heining, And P. Kline (2013): "Workplace Heterogeneity and the Rise of West German Wage Inequality," Quarterly Journal of Economics, 128, 967-1015.

Card, D. E., A. Mas, E. Moretti, And E. SAez (2012): "Inequality at Work: The Effect of Peer Salaries on Job Satisfaction," American Economic Review, 102, 2981-3003.

Carpenter, J., P. Matthews, and J. Schrim (2010): "Tournaments and Office Politics: Evidence from a Real-effort Experiment," American Economic Review, 100, 504-517. 
Cohn, A., E. Fehr, B. Herrmann, And F. Schneider (2011): "Social Comparison in the Workplace: Evidence from a Field Experiment," Unpublished manuscript, University of Zurich.

Currarini, S., M. O. Jackson, And P. Pin (2009): "An Economic Model of Friendship: Homophily, Minorities, and Segregation," Econometrica, 77, 1003-1045.

Dearden, L., H. Reed, and J. Van Reenen (2006): "The Impact of Training on Productivity and Wages: Evidence from British Panel Data," Oxford Bulletin of Economics and Statistics, 68, 397-421.

Drago, R. and G. T. Garvey (1998): "Incentives for Helping on the Job: Theory and Evidence," Journal of Labor Economics, 16, 1-25.

Eeckhout, J. And P. Kircher (2011): "Identifying Sorting - In Theory," Review of Economic Studies, 78, 872-906.

Ekeland, I., J. J. Heckman, And L. Nesheim (2002): "Identifying Hedonic Models," American Economic Review Papers \& Proceedings, 92, 304-309.

— (2004): "Identification and Estimation of Hedonic Models," Journal of Political Economy, 112, S60-S109.

Encinosa, W. E., M. Gaynor, and J. B. Rebitzer (2007): "The Sociology of Groups and the Economics of Incentives: Theory and Evidence on Compensation Systems," Journal of Economic Behavior \&3 Organization, 62, 187-214.

Farrell, J. ANd S. Scotchmer (1988): "Partnerships," Quarterly Journal of Economics, 103, 279-298.

Fehr, E. And K. M. Schmidt (2006): "The Economics of Fairness, Reciprocity and Altruism: Experimental Evidence and New Theories," in Handbook of the Economics of Giving, Altruism, and Reciprocity, ed. by S.-C. Kolm and J. M. Ythier, Elsevier, vol. 1, 615-691.

Fujita, M. (1989): Urban Economic Theory: Land Use and City Size, New York, NY: Cambridge University Press. 
Gibbons, R. And M. Waldman (1999): "A Theory of Wage And Promotion Dynamics Inside Firms," Quarterly Journal of Economics, 114, 1321-1358.

Goux, D. And E. Maurin (1999): "Persistence of Interindustry Wage Differentials: A Reexamination Using Matched Worker-Firm Panel Data," Journal of Labor Economics, 17, $492-533$.

Gruetter, M. and R. Lalive (2009): "The Importance of Firms in Wage Determination," Labour Economics, 16, 149-150.

Hamilton, B. H., J. A. Nickerson, And H. Owan (2003): "Team Incentives and Worker Heterogeneity: An Empirical Analysis of the Impact of Teams on Productivity and Participation," Journal of Political Economy, 111, 465-497.

Heckman, J. J. (1979): "Sample Selection Bias as a Specification Error," Econometrica, 47, $153-161$.

Hibbs, D. A. And H. Locking (2000): "Wage Dispersion and Productive Efficiency: Evidence for Sweden," Journal of Labor Economics, 18, 755-782.

Ichino, A. And G. MagGi (2000): "Work Environment and Individual Background: Explaining Regional Shirking Differentials in a Large Italian Firm," Quarterly Journal of Economics, 115, 1057-1090.

IOANnides, Y. M. (2008): "Full Solution of an Endogenous Sorting Model with Contextual and Income Effects," Unpublished manuscript, Tufts University.

— (2011): "Neighborhood Effects and Housing," in Handbook of Social Economics, ed. by J. Benhabib, A. Bisin, and M. O. Jackson, New York: Elsevier, 1281-1340.

Kandel, E. And E. P. Lazear (1992): "Peer Pressure and Partnerships," Journal of Political Economy, 100, 801-817.

Lallemand, T., R. Plasman, and F. Rycx (2009): "Wage Structure and Firm Productivity in Belgium," in The Structure of Wages: An International Comparison, ed. by E. P. Lazear and K. L. Shaw, Chicago, IL: University of Chicago Press, 179-215. 
Lazear, E. P. (1989): "Pay Inequality and Industrial Politics," Journal of Political Economy, $87,1261-1284$.

(1998): Personnel Economics for Managers, New York, NY: Wiley.

Lazear, E. P. And S. Rosen (1981): "Rank-order Tournaments as Optimum Labor Contracts," Journal of Political Economy, 89, 841-864.

LAzeAR, E. P. And K. L. Shaw (2007): "Personnel Economics: The Economist View of Human Resources," Journal of Economic Perspectives, 21, 91-114.

Ledford, G. E., E. E. Lawler, and S. A. Mohrman (1995): "Reward Innovations in Fortune 1000 Companies," Compensation and Benefits Review, 27, 76-80.

Levine, D. I. (1991): "Cohesiveness, Productivity, and Wage Dispersion," Journal of Economic Behavior $\&$ Organization, 15, 237-255.

Manski, C. F. (1993): "Identification of Endogenous Social Effects: The Reflection Problem," Review of Economic Studies, 60, 531-542.

- (2000): "Economic Analysis of Social Interactions," Journal of Economic Perspectives, $14,115-136$.

Marmaros, D. And B. Sacerdote (2006): "How Do Friendships Form?" Quarterly Journal of Economics, 121, 79-119.

Marshall, A. (1890): Principles of Economics, London, UK: Macmillan.

Mas, A. And E. Moretti (2009): "Peers at Work," American Economic Review, 99, 112145.

McLaughlin, K. (1988): "Aspects of Tournaments Models: A Survey," Journal of Labor Economics, 15, 403-430.

McPherson, M., L. Smith-Lovin, And J. M. Cook (2001): "Birds of a Feather: Homophily in Social Networks," Annual Review of Sociology, 27, 415-444. 
Milgrom, P. (1988): "Employment Contracts, Influence Activities, and Efficient Organisation Design," Journal of Political Economy, 96, 42-60.

Milgrom, P. And P. J. Roberts (1990): "Rationalizability, Learning, and Equilibrium in Games with Strategic Complementarities," Econometrica, 58, 1255-1277.

Nesheim, L. (2001): "Equilibrium Sorting of Heterogeneous Consumers Across Locations: Theory and Empirical Implications," Ph.D. thesis, University of Chicago.

Prat, A. (2002): "Should a Team Be Homogeneous?" European Economic Review, 46, $1187-1207$.

Rosen, S. (1974): "Hedonic Prices and Implicit Markets: Product Differentiation in Pure Competition," Journal of Political Economy, 82, 34-55.

Ross, S. L. And J. Yinger (1999): "Sorting and Voting: A Review of the Literature on Urban Public Finance," in Handbook of Regional and Urban Economics, ed. by E. S. Mills and P. Cheshire, New York, NY: Elsevier.

Sala, H. AND J. I. Silva (2012): "Labor Productivity and Vocational Training: Evidence from Europe," Journal of Productivity Analysis, 40, 31-41.

TinBergen, J. (1956): "On the Theory of Income Distribution," Weltwirtschaftliches Archiv, $77,155-175$.

Tumen, S. (2011): "Essays on Endogenous Social Effects," Ph.D. thesis, University of Chicago.

(2012): "Fertility Decisions and Endogenous Residential Sorting," Regional Science and Urban Economics, 42, 78-87. 


\begin{tabular}{l|ccccc}
\hline \hline Outcome & \multicolumn{5}{c}{ Parameter Values } \\
\hline & $\eta=0.3$ & $\eta=0.4$ & $\eta=0.5$ & $\eta=0.6$ & $\eta=0.7$ \\
\hline Average wage & 130.10 & 125.43 & 123.29 & 122.84 & 123.66 \\
Average profit (per job) & 89.31 & 93.57 & 95.41 & 95.65 & 94.41 \\
Average group-level productivity & 1.32 & 1.31 & 1.30 & 1.30 & 1.29 \\
St. Dev. of wage & 33.13 & 30.68 & 29.81 & 29.95 & 30.87 \\
St. Dev. of profit (per job) & 28.61 & 26.21 & 25.39 & 25.59 & 26.59 \\
St. Dev. of group-level productivity & 0.94 & 0.91 & 0.89 & 0.88 & 0.87 \\
\hline & $\beta=0.3$ & $\beta=0.4$ & $\beta=0.5$ & $\beta=0.6$ & $\beta=0.7$ \\
\hline Average wage & 67.80 & 94.15 & 123.29 & 155.91 & 192.75 \\
Average profit (per job) & 141.26 & 119.27 & 95.41 & 69.08 & 39.60 \\
Average group-level productivity & 1.30 & 1.30 & 1.30 & 1.30 & 1.30 \\
St. Dev. of wage & 13.54 & 20.68 & 29.81 & 41.48 & 56.47 \\
St. Dev. of profit (per job) & 11.09 & 17.29 & 25.39 & 35.93 & 49.65 \\
St. Dev. of group-level productivity & 0.89 & 0.89 & 0.89 & 0.89 & 0.89 \\
\hline & $\sigma_{e s}=0.3$ & $\sigma_{e s}=0.4$ & $\sigma_{e s}=0.5$ & $\sigma_{e s}=0.6$ & $\sigma_{e s}=0.7$ \\
\hline Average wage & 189.93 & 146.86 & 123.29 & 108.97 & 99.59 \\
Average profit (per job) & 28.21 & 71.57 & 95.41 & 109.96 & 119.51 \\
Average group-level productivity & 1.33 & 1.31 & 1.30 & 1.29 & 1.29 \\
St. Dev. of wage & 76.91 & 44.75 & 29.81 & 21.79 & 17.02 \\
St. Dev. of profit (per job) & 72.64 & 40.37 & 25.39 & 17.38 & 12.65 \\
St. Dev. of group-level productivity & 1.08 & 0.98 & 0.89 & 0.83 & 0.77 \\
\hline \hline
\end{tabular}

Table 2: Simulation Results. The upper panel fixes $\beta=0.5$ and $\sigma_{e s}=0.5$. The upper panel fixes $\eta=0.5$ and $\sigma_{e s}=0.5$. The lower panel fixes $\eta=0.5$ and $\beta=0.5$. The data is generated from 10,000 draws from the standard normal random variables $\sigma_{e}$ and $\sigma_{s}$, and the draws are correlated in the order of the covariance $\sigma_{e s}$. The fixed parameters in this exercise are $A=200$ and $L=1$. Note that the group-level productivity, $x$, is an index and its magnitude is not comparable with wages and profits. 